\title{
A Rare Case of Intramedullary Epidermoid Cyst at Conus with the Review of Literature
}

\author{
Rajesh Uddandam $^{1}$, Vivek Khandelwal ${ }^{2}$, Saurabh Maheshwari ${ }^{3}$, Varun Anand ${ }^{4}$ \\ ${ }^{1-4}$ Department of Radiology, AFMC, Pune, India \\ Corresponding Author: Vivek Khandelwal
}

DOI: https://doi.org/10.52403/ijrr.20220223

\begin{abstract}
Summary: We present a case of young male who presented with history of gradually progressive low backache and bladder incontinence. Clinically he was diagnosed as a case of cauda-conus syndrome. Imaging revealed an intramedullary cystic lesion at conus medullaris with features favoring epidermoid cyst. The diagnosis was confirmed on histopathological examination.
\end{abstract}

Keywords: Epidermoid cyst, Spine, Intramedullary, Conus Medullaris, Magnetic resonance imaging

\section{BACKGROUND}

Spinal epidermoid cysts are rare lesions. They can be extradural, intraduralextramedullary, or intramedullary in locations with the intramedullary form being the rarest. There have been only about 80 reported cases of the intramedullary epidermoid cysts in the literature till now. We present a rare case of an intramedullary spinal epidermoid cyst in the conus medullaris with post-operative findings and a review of the relevant literature.

\section{CASE PRESENTATION}

A 22 years old male patient presented to our hospital with a history of gradually progressive low backache. This was associated with a history of bladder incontinence. There was no history of trauma or previous surgery. On clinical examination, the skin overlying the thoracic and lumbar region was normal. Motor examination revealed weakness at the ankle joints and hypoesthesia from L4 to S2 dermatomes in the distribution of the dorsal column as well as anterolateral pathways. Ankle jerks were absent bilaterally. There was no sensory deficit. The patient underwent imaging with a clinical suspicion of Cauda-conus syndrome.

\section{Investigation}

Magnetic resonance imaging (MRI) of the lumbosacral spine revealed a welldefined intra-medullary lesion in the region of conus medullaris. It extended from the inferior body of LV1 to the superior body of LV3. The lesion was expanding the cord. It was heterogeneously hyperintense on both T1WI \&T2WI and showed restriction of diffusion on diffusion-weighted images (DWI). No post-contrast enhancement was seen. The lesion was causing posterior scalloping of the L2 vertebral body (Fig 1).

Non-contrast computed tomography (NCCT) of the dorso-lumbar spine showed soft tissue density lesion in the spinal canal extending from LV1 to LV3 causing the widening of the spinal canal and scalloping of posterior vertebral body margin of L2. No destruction of the bone was seen. (Fig 2). 


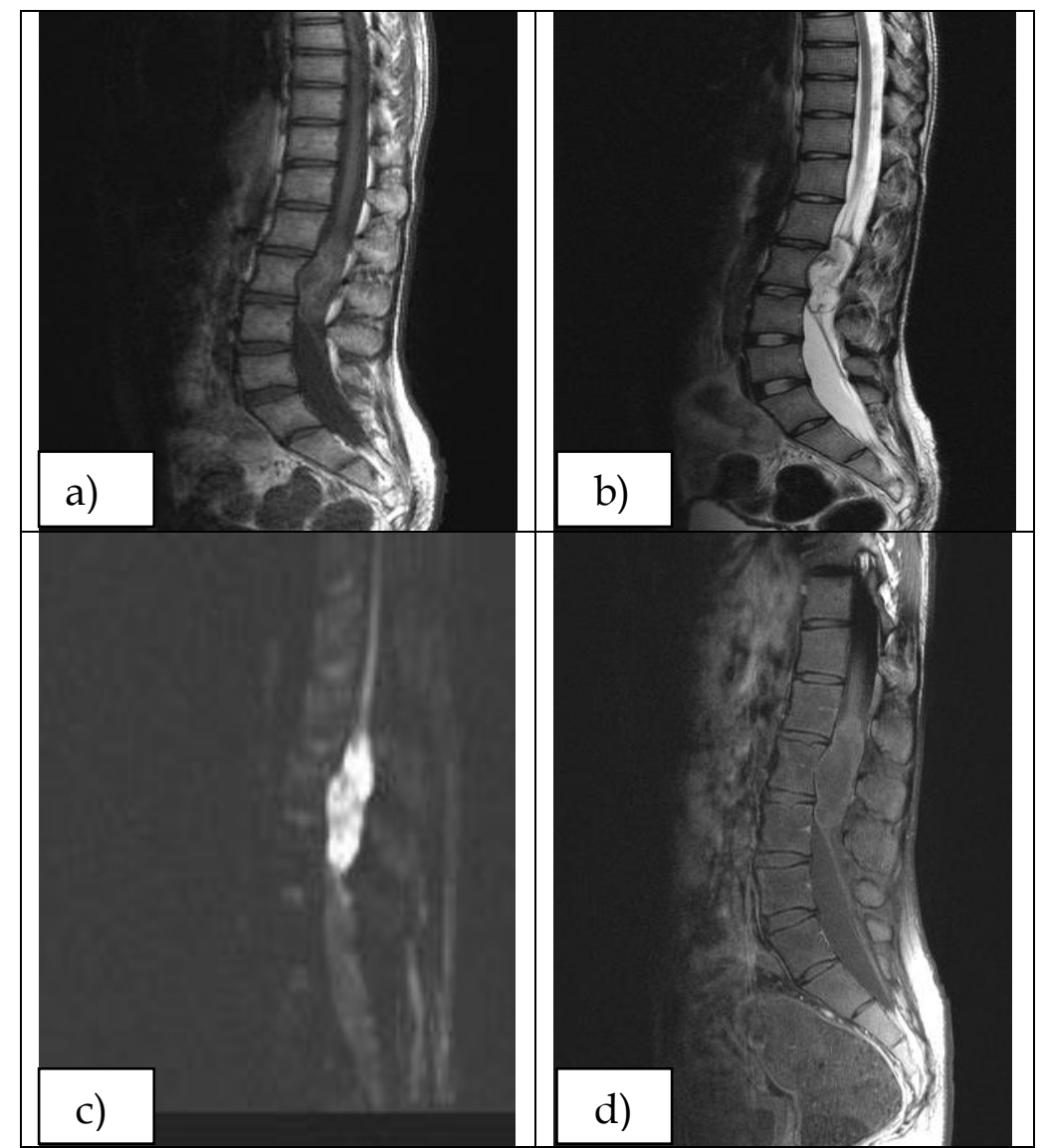

Figure 1- MRI of lumbosacral spine. a, b) T1WI \&amp; T2WI sagittal section of lumbosacral spine shows heterogeneously hyperintense lesion in the region of conus medullaris expanding the cord. c) Restriction of diffusion is seen with lesion appearing bright on DWI. d) No post-contrast enhancement is seen.

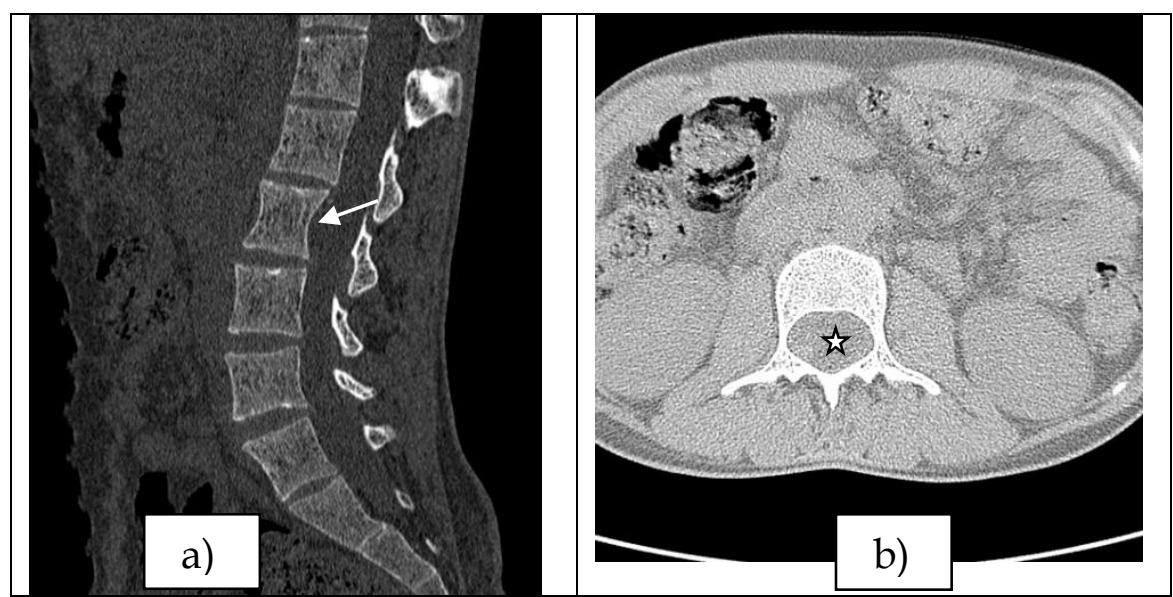

Figure 2: NCCT of lumbosacral spine a) Sagittal reformat in bone window showing lesion is seen in the spinal canal posterior to $\mathrm{L} 2$ vertebral body, causing widening of the spinal canal with associated scalloping (white solid arrow). No destruction of the bone is seen. b) Axial reformat in soft tissue window showing a soft tissue density intramedullary lesion in the spinal canal posterior to $\mathbf{L 2}$ vertebral body (Asterisk *).

\section{Diagnosis:}

Intramedullary epidermoid cyst

\section{Treatment}

The patient underwent L1 to L4 laminectomy and excision of the lesion. Intra-operatively, the conus was seen to be widened. A midline dorsal myelotomy was performed. It revealed a pearly white and flaky lesion within the cord substance. Using microsurgical techniques, near-total excision of the lesion was done. At places, the capsule of the lesion was seen adherent to adjacent tissues, and care was taken to prevent any damage to adjacent tissues. 
On histopathological examination (HPE), the lesion was composed of keratin flakes and lined by squamous epithelium with a distinct granular layer. It confirmed the diagnosis of epidermoid (Fig 3). At two months follow up, the patient was symptomatically better with the resolution of backache and continent bladder.

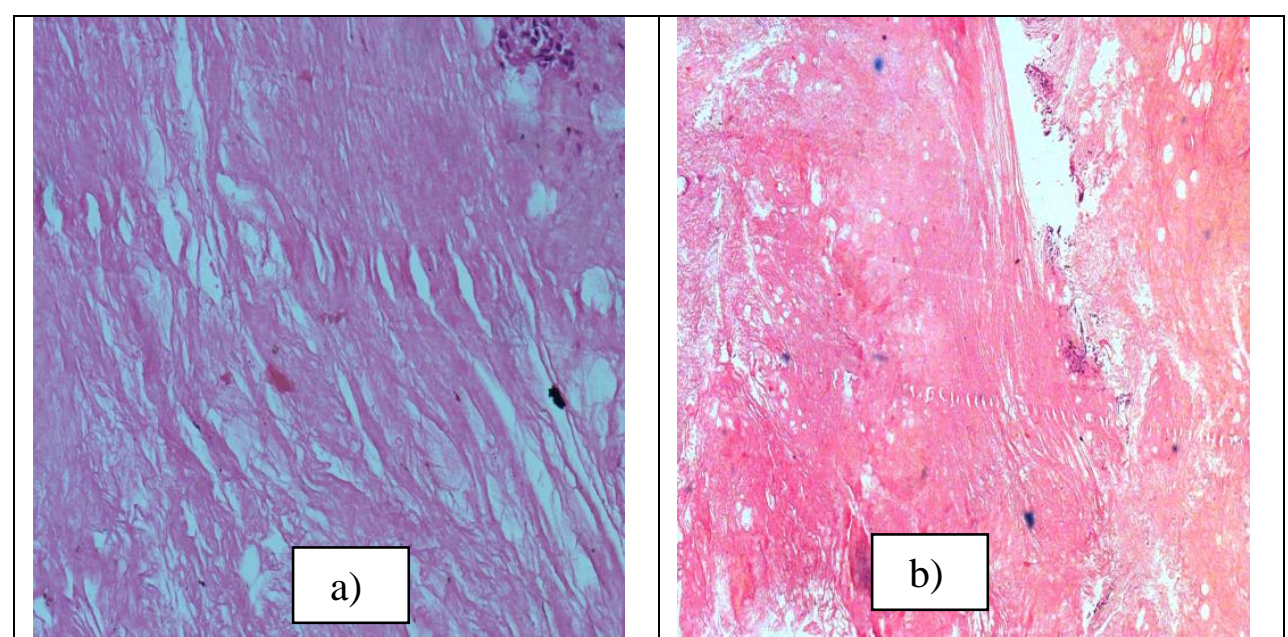

Figure 3: Photomicrograph of HPE section of the lesion. a) \& b) H\&E stain showing homogenous, acellular, eosinophilic lamellated keratin flakes.

\section{Outcome and follow up}

Patient was kept under 6 month follow up. On regular follow up, patient was asymptomatic. Clinical examination showed no focal motor or sensory deficit.

\section{DISCUSSION}

Spinal epidermoid cysts are rare tumors, which can be either congenital or acquired. The congenital variant occurs due to the inclusion of ectodermal tissue at the time of neural tube closure ${ }^{[1,2,3]}$. The congenital variant is usually associated with other spine pathologies like dermoid tracts, occult spinal dysraphism, spinal bifida aperta, and hemivertebra. Whereas acquired epidermoid cysts occurs secondary to iatrogenic penetration of skin fragments after spinal surgeries or invasive procedures like lumbar puncture ${ }^{[4,5]}$. Our patient gave no history of spinal surgery or lumbar puncture, suggesting the etiology in our case to be congenital.

Clinical features of the patient depend on the level of spine involvement. Patients usually present with low backache with radiation to lower limbs, sensory loss, bladder \& bowel disturbance, and absent deep tendon jerks. The cyst grows slowly over time, resulting in delayed presentation
$\&$ diagnosis ${ }^{[6,7]}$. In our case, the patient presented with low backache \& urinary incontinence and had signs of Cauda-conus syndrome.

MRI is the commonest investigation used for the diagnosis. Epidermoid cysts are generally hypointense on T1WI, hyperintense on T2WI, and show peripheral post-contrast enhancement ${ }^{[8,9]}$. Restricted diffusion is seen in diffusion-weighted images (DWI). Computed tomography is less commonly used and may show soft tissue density lesion in the spinal cord with bony scalloping. Imaging findings in our case were highly suggestive of an intramedullary spinal epidermoid cyst.

HPE is essential for confirmation of imaging diagnosis of epidermoid cysts and helps in differentiating them from dermoid cysts. Epidermoid cysts contain keratin and are lined with stratified squamous keratinizing epithelium with surrounding collagenous tissue. They do not contain skin adnexa. In contrast, dermoid cysts contain adnexal skin structures like hair follicles, eccrine glands, and sebaceous glands ${ }^{[10,11]}$. HPE examination in our patient was confirmatory of an epidermoid cyst.

Treatment depends upon the symptoms of the patient. Asymptomatic 
patients can be managed conservatively. The total surgical excision of a spinal epidermoid cyst is the curative treatment, especially in symptomatic patients and in patients in whom imaging shows compression of neural elements ${ }^{[12]}$. Subtotal resection is done in patients in whom the capsule is adherent to surrounding tissues. Complete resection in these cases may lead to neurological deficits ${ }^{[13,14]}$. In our patient, subtotal resection was done, as the capsule was densely adherent to adjacent tissues. Since the tumor is benign, the prognosis is good. Local recurrence has been reported after subtotal excision and it depends on the magnitude of resection [15, 16]. Long-term follow up is hence advised to look for recurrence.

\section{Teaching point}

Spinal intramedullary epidermoid cysts are rare and MRI is the investigation of choice for their diagnosis. The treatment of choice is total surgical resection. However, in patients having adhesions with adjacent tissues, subtotal resection should be done to prevent neurological deficits. The purpose of this paper is to highlight the fact that although rare, the intramedullary epidermoid cyst should be suspected in a young patient presenting with low backache.

\section{Authors' Contributions}

Rajesh Uddandam- Senior radiologist primarily involved in diagnosing and reporting the case.

Vivek Khandelwal- Senior resident coreporter in diagnosing and reporting the case.

Saurabh Maheshwari- Senior resident involved in histopathological findings of the case.

Varun Anand- Senior resident involved in the follow up of the patient.

\section{Acknowledgement: None}

Conflict of Interest: None

Source of Funding: None

\section{REFERENCES}

1. Graillon $\mathrm{T}$, Rakotozanany $\mathrm{P}$, Meyer $\mathrm{M}$, Dufour H, Fuentes S. Intramedullary epidermoid cysts in adults: Case report and updated literature review. Neurochirurgie. 2017 May; 63(2):99-102. doi: 10.1016/j.neuchi.2017.01.004. Epub 2017 May 8. PMID: 28495229

2. Somasundaram A, Lesser GJ, Mott RT, Hsu W. Malignant transformation of an intramedullary epidermoid cyst in the thoracic region of the spinal cord: case report. J Neurosurg Spine. 2013 Nov;19(5):591-4.

doi:10.3171/2013.8.SPINE13150. PMID: 24053372

3. Fereydoonian NA, Bakhti S, Fereshtehnejad SM, Tabibkhooei AR. Intramedullary thoracic spine epidermoid cyst with myelopathic presentations: a report of a rare case. Clin Neurol Neurosurg. 2013 Jun; 115(6):841-3. doi: 10.1016/j.clineuro.2012.08.002. PMID: 22959213

4. Akgun B, Ergun AC, Ozercan IH, KokS. IntraduralExtramedullary Epidermoid Cyst at the Conus Medullaris level with Thoracic Syringomyelia: a Case Report. ActaMedica (Hradec Kralove). 2019;62(1):39-42. doi: 10.14712/18059694.2019.45. PMID: 30931896

5. Kansal R, Mahore A, Dange N. Giant intramedullary epidermoid extending from the brain stem to the upper thoracic spinal cord. Turk Neurosurg. 2012;22(4):452-3. doi: 10.5137/10195149.JTN.3096-10.2. PMID: 22843463

6. Gotecha S, Ranade D, Sharma S, Punia P, Kotecha M. Giant intradural intramedullary epidermoid cyst Report of two cases with varied presentations. Asian $\mathrm{J}$ Neurosurg 2014; 9: 244. doi: 10.4103/17935482.146653. PMID: 25685236

7. Yoon SH, Jahng TA, Kim KJ, Chung CK, Kim HJ. An extensive intramedullary epidermoid cyst wi th a longstanding history of paraplegia: a case report. J NeurolSurg A Cent EurNeurosurg. 2013 Dec;74Suppl 1:e1-3. doi: $10.1055 / \mathrm{s}-0032-1304221$. PMID: 22777928

8. Funao $\mathrm{H}$, Isogai $\mathrm{N}$, Daimon $\mathrm{K}$, et al. A rare case of intradural and extramedullary epidermoid cyst after repetitive epidural anesthesia: case report and review of the 
literature. World Journal of Surgical Oncology 2017; 15: 131. doi: 10.1186/s12957-017-1186-4. PMID: 28716031

9. Agarwal A, Bhake A, Kakani A. Cervical intramedullary epidermoid cyst wit $\mathrm{h}$ liquid contents. Asian Spine J. 2011 Mar;5(1):59-63. doi: 10.4184/asj.2011.5.1.59. PMID: 21386947

10. Mishra SS, Satapathy MC, Deo RC, Tripathy SR, Senapati SB. Isolated thoracic (D5) intramedullary epidermoid cyst without spinal dysraphism: A rare case report. J PediatrNeurosci 2015; 10: 133-6. doi: 10.4103/1817-1745.159206. PMID: 26167216

11. Fleming C, Kaliaperumal C, O'Sullivan M. Recurrent intramedullary epidermoid cyst of conus medullaris. BMJ Case Rep. 2011 Dec 13;2011. pii: bcr1120115090. doi:10.1136/bcr.11.2011.5090. PMID: 22669964

12. Brohi SR, Qureshi SM, Rajput SS, Bhatti NK.

Thoracic intramedullary epidermoid with paraplegia for 12 years. J Coll Physicians Surg Pak. 2010 Feb;20(2):135-6. doi:02.2010/JCPSP.135136. PMID: 20378045

13. Cincu R, Lázaro JF, Liesa JL, Callizo JR. Dorsal intramedullary spinal epidermoid cysts; Report of two cases and review of literature. Indian J Orthop. 2007 Oct;41(4):395-7. doi: 10.4103/00195413.37005. PMID: 21139798

14. Kumar A, Singh P, Jain P, Badole CM. Intramedullary spinal epidermoid cyst of the cervicodorsal region: A rare entity. J PediatrNeurosci. 2010 Jan;5(1):49-51. doi: 10.4103/1817-1745.66675. PMID: 21042510

15. Gonzalvo A, Hall N, McMahon JH, Fabinyi GC. Intramedullary spinal epidermoid cyst of the upper thoracic region. J Clin Neurosci. 2009;16:142-4. doi: 10.1016/j.jocn.2008.04.017. Epub 2008 Nov 14. PMID: 19013801

16. Ogden AT, Khandji AG, McCormick PC, Kaiser MG. Intramedullary inclusion cysts of the cervicothoracic junction. Report of two cases in adults and review of the literature. $\mathrm{J}$ Neurosurg Spine. 2007 Aug;7(2):236-42. Review. PMID: 17688066

How to cite this article: Uddandam R, Khandelwal V, Maheshwari S et.al. A rare case of intramedullary epidermoid cyst at conus with the review of literature. International Journal of Research and Review. 2022; 9(2): 160-164. DOI: https://doi.org/10.52403/ijrr.20220223 